\title{
Variability of Physical and Biogeochemical parameters in the Exclusive Economic Zone of Qatar
}

V.M. Aboobackera, Fazle Rakibb, Ebrahim M.A.S. Al-Ansaria, Y.S. Husrevogluc, Oguz Yigiterhana, Ibrahim Al-Maslamanid, Ponnumony Vethamony
a Environmental Science Center, Qatar University, Doha, P.O. Box: 2713, State of Qatar. o Department of Biological and Environmental Sciences, Qatar University, Doha, P.O. Box: 2713, State of Qatar. c Institute of Marine Sciences, Middle East Technical University,
33731 , Erdemli, Mersin, Turkey. doffice of Vice President for Research and Graduate Studies, Qatar University, P.O. Box: 2713, State of Qatar.

\section{Abstract}

The oceanographic data collected along a transect in the Exclusive Economic Zone (EEZ) of Qatar during late summer (September 2014) and winter (January 2015) have been analyzed to investigate the spatial and temporal variability of hydrography and biogeochemistry. The study reveals that stratification is dominant in the deep water regions during September, with a vertical variation of around $9^{\circ} \mathrm{C}$ from surface to bottom. However, the wate column remains in homogeneity during January due to strong wind mixing and surface cooling. The dissolved oxygen (DO) in the upper layer of the EEZ is on a reasonable range in both the seasons, while they gradually decrease with respect to depth in the mid and bottom layers during January. This leads to hypoxic conditions in summer. Chlorophyll- a (Chl- a ) is relatively high during summer in the offshore region, while that in the nearshor region is very low. The variability in the physical and biogeochemical parameters has shown significant effects in the primary productivity in the EEZ of Qatar.

\section{Background}

Understanding regional and seasonal hydrography and biogeochemistry is essential to predict the effects of environmental stressors and global climate change. Water column structure and distribution of water masses determine properties and status of various habitats. Assessment of seawater quality, marine productivity and ecological status is performed by monitoring physical and biogeochemical parameters such as temperature, salinity, density, dissolved oxygen (DO), chlorophyll-a (Chl-a) and water masses. The present study aims at investigating the variabilities in the above physical and biogeochemical parameters in two different seasons (summer and winter) and variabilities in the above physical and biogeochemical parameters in two different seasons (summer and winter) and
the role of currents in the transport of these variables. The significance of this work stems out from the following studies: (i) Regional and seasonal hydrography in the prediction of effects of environmental stress and global change, (ii) water column structure and water mass distribution to determine the properties and status of various habitats and (iii) assessment of water quality, marine productivity and ecological status by monitoring marine biogeochemical parameters.
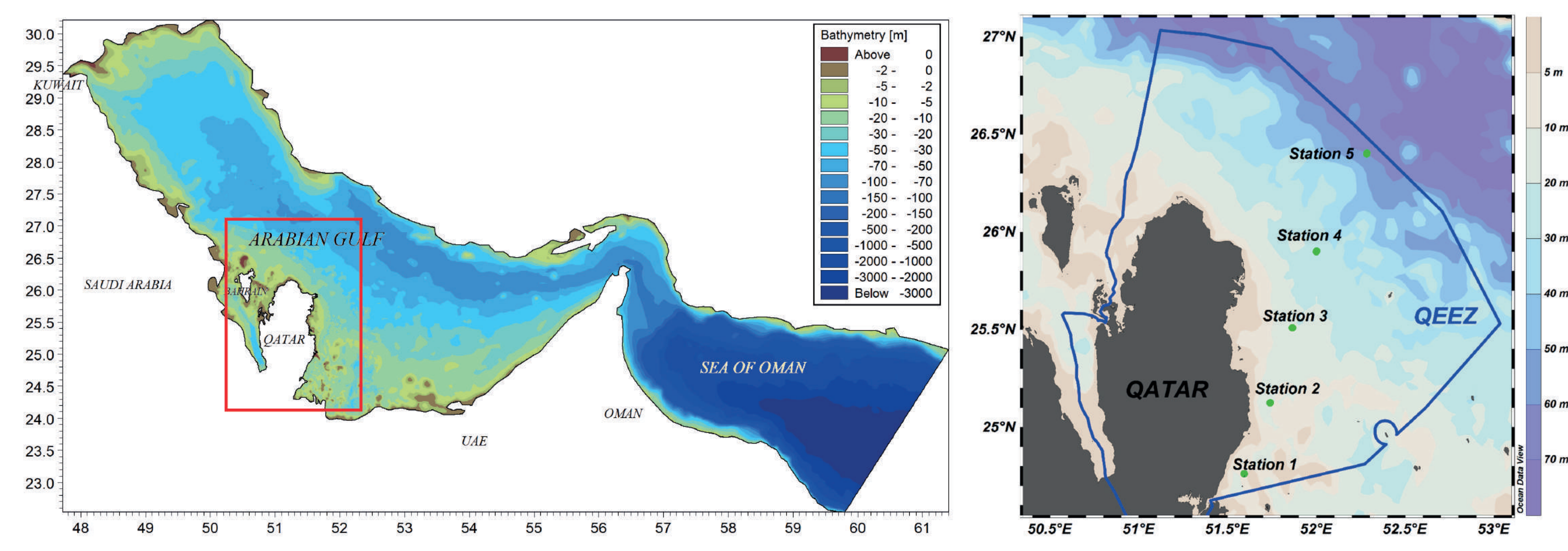

Area of study

Qatar Peninsula is located at the central Gulf with approximate dimensions of $85 \times 160 \mathrm{~km}$ (area: $\approx 11,437 \mathrm{~km}^{2}$ ) projecting northwards from the Arabian Peninsula into the Gulf, centred at $25^{\circ} \mathrm{N}$ and $51^{\circ} \mathrm{E}$ (Figure 1). The geographical setting of Qatar peninsula firmly influences the currents, waves and sedimentation pattern along the central and southern Gulf. Several other elements of the ecosystem such as biological productivity and nutrient regeneration might also be influenced by physical and geographical settings ( Al-Ansari, 2006 ).

Data and Methods

The vertical profiles of physical variables in the water column were measured using Conductivity-Temperature-Depth (CTD) system (SBE-911plus CTD) onboard R/V Janan in September 2014 and January 2015 (hereafter referred to as late summer and winter, repectively) at five sampling locations (Figure 1), representing different water masses. The density, often represented by potential density (sigmat), has been obtained from the CTD records using the formula described in Fofonoff and Millard (1983). Sea water samples for the analysis of biogeochemical parameters, DO and Chl-a, were collected using new, acid cleaned PVC-Niskin bottles of 12-litre capacity, attached to the Seabird CTD system. Multiple samples were collected from each sampling location at different depths.

The protocol described by Parsons et al. (1984) was followed for sample preparation, and further analyses were carried out in the laboratory using classic Winkler method (Winkler, 1888). For the determination of Chl-a, the samples were filtered through 47 $\mathrm{mm}$ diameter, $0.45 \mu \mathrm{m}$ Millipore nitrocellulose membrane filters in reduced light using Millipore glass filtration apparatus.

Results

Seasonal variations

The temperature variations during late summer and winter are $23.5-33.3^{\circ} \mathrm{C}, 19.3-22.3^{\circ} \mathrm{C}$, respectively, where higher horizontal and vertical variability is found during late summer (Figures 2 and 3 ).

There exists seasonal difference in salinity, although it is small, 38.85-45.70 and 40.09-45.88, respectively during late summer and winter, respectively. However, the vertical variation in salinity (a difference of 1.14) in the deepest station (Stn. 5) during late summer is not strong enough to have a well-defined stratification.

Potential densities during late summer and winter are $23.626-28.575 \mathrm{~kg} / \mathrm{m}^{3}$ and $28.004-33.195 \mathrm{~kg} / \mathrm{m}^{3}$, respectively. The higher densities of each season are found in the nearshore station (Stn. 1), where the impact of brine discharge is significant.
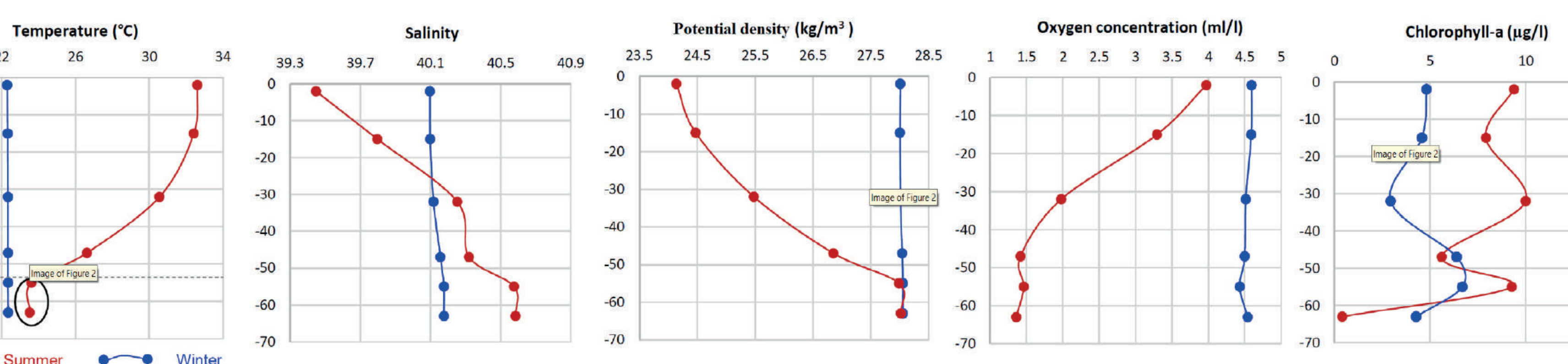

Figure 2. Vertical profile of temperature, salinity, density, DO and Chl-a at Station

The DO concentration during late summer $(1.41-4.25 \mathrm{~mL} / \mathrm{L})$ is lower than winter $(4.43-5.06 \mathrm{~mL} / \mathrm{L})$ in the EEZ of Qatar. The strong winds during winter generate turbulence, which brings more oxygen to the subsurface, leading to vertical homogeneity and conserved DO.

The Chl-a concentration in the EEZ of Qatar during late summer varies between $0.41 \mu \mathrm{g} / \mathrm{L}$ and $10 \mu \mathrm{g} / \mathrm{L}$, and during winter varies between $2.91 \mu \mathrm{g} / \mathrm{L}$ and $6.69 \mu \mathrm{g} / \mathrm{L}$. This shows higher spatial variability during late summer than winter, because the nearshore regions (Stns. 1 and 2) have much lower Chl-a concentration during late summer.

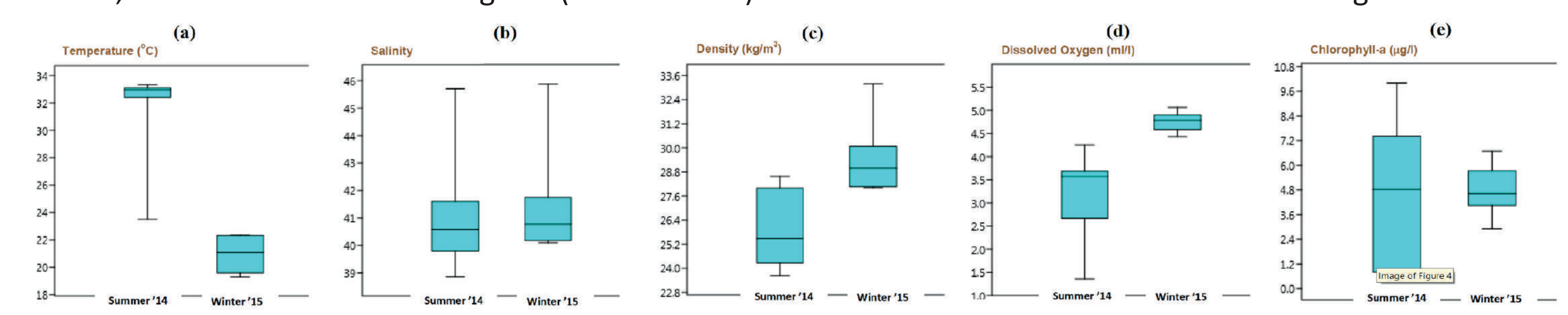

Water masses observed in the EEZ of Qatar

The analysis reveals the existence of a few water masses in the Gulf in late summer with very distinct physical properties. They are: (i) Qatari Deep Water (QDW) that prevails below the summer thermocline, (ii) Gulf of Salwa Outflow Water (GSW), (iii) Open Qatari Water (OQW) and (iv) South-eastern Qatari Water (SEQW) (Figure 4). These water masses within the Gulf are balanced by warm, low salinity Gulf of Oman Water (WLSOW), which is a surface inflow from the Sea of Oman characterized by low density. It is more pronounced during late summer than winter. The excess heating within the Gulf over the inflow of WLSOW leads to further increase in salnity and (Al-Ansari et al., 2015

\section{Discussion}

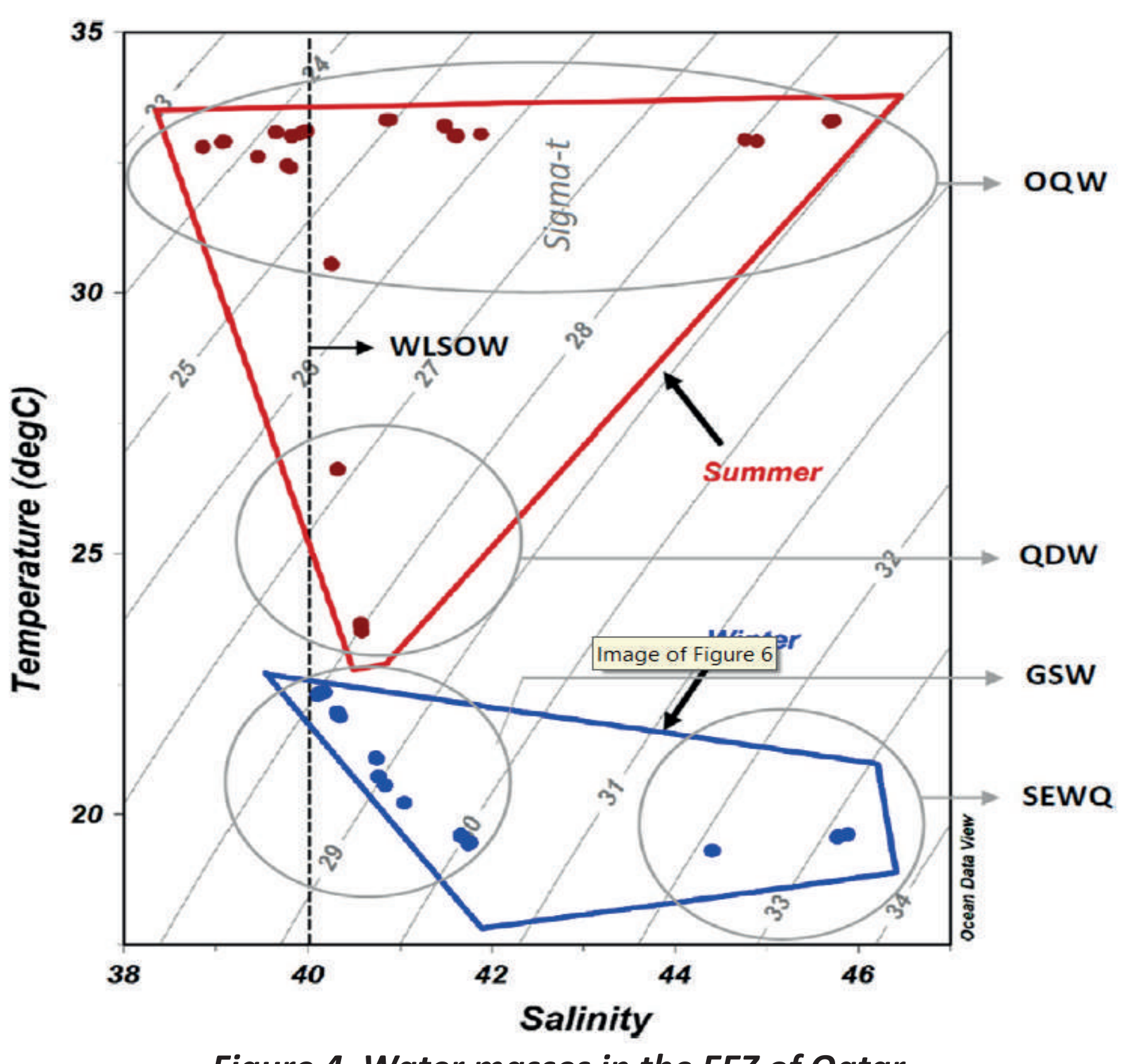

The EEZ of Qatar is affected by excessive heating of the sun, resulting in the formation of warm surface layer characterized with low density, which is separated from the bottom cold water by the seasonal thermocline layer (Figure 5). Though sea water temperature is lower during winter, higher evaporation occurs due to strong winds, especially due to winter shamal winds (Reynolds, 1993), leading to mixing of the water column.

The cumulative effect of brine discharges in the recent decades along the Arabian coast is evident from the exceptional salinity distributions at respective coastal areas (Ibrahim et al., 2020).

The large difference in salinity and density found between the nearshore and offshore stations, indicate that anthropogenic effects, especially the brine discharge, determine the density variations near the coast. Higher stress from onshore/nearshore anthropogenic sources may gradually advect to the adjacent nearshore/offshore region over a period of time, which may further impact the ecosystem.
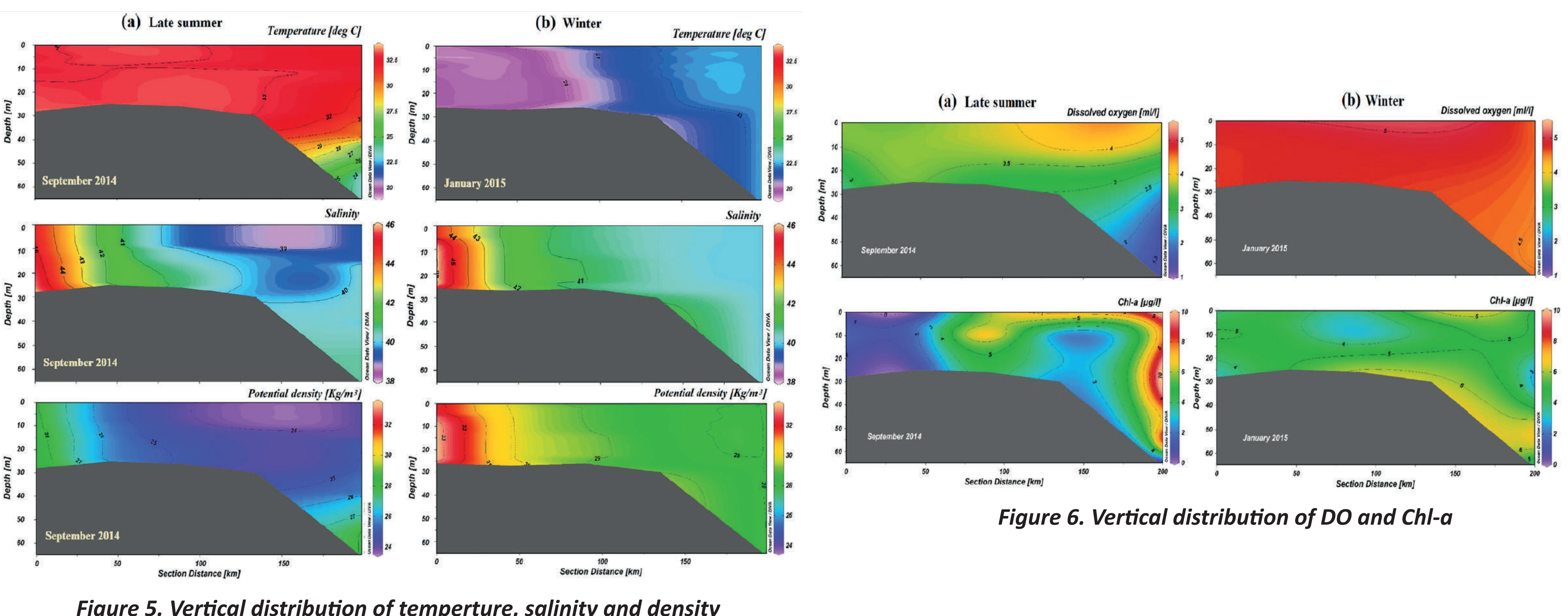

The vertical distribution of DO in the offshore station is in direct proportion with that of temperature, and inverse proportion with that of salinity and density, indicating that changes in DO are linked with changes in physical variables. There exists distinct variability in DO in the EEZ of Qatar among the two seasons as seen in the physical variables. The impact of the water masses (Figure 6) along with the seasonal heating/winds are quite evident in this variability Typically, DO is a representative of a healthy and functioning ecosystem supporting aquatic life (Desa et al., 2005). The mean DO concentrations in the surface layers along the transect in the EEZ of Qatar are $3.85 \mathrm{~mL} / \mathrm{L}$ and $4.90 \mathrm{~mL} / \mathrm{L}$ during late summer and winter, respectively, which is slightly lower than that observed in a well-oxygenated region in the Gulf (Al-Ansari, 2006).

It is observed that the nutrient levels are low in the euphotic zone of the EEZ of Qatar and Chl-a is generally nutrient-limited throughout the year (Al-Ansari, 2006). In the thermocline layer, with the presence of oxygen and sufficient sunlight, the nutrient concentration increases in the subsurface, allowing it to increase the Chl-a at the intermediate depths during late summer. However, in the bottom layers, though nutrients are high, the absence of oxygen and sunlight restricts the values of $\mathrm{Chl}-\mathrm{a}$, and hence lower values are observed.

The very low wind speeds during September (Aboobacker et al., 2020) restrict mixing of water column, and subsequently advection through wind induced currents in these regions. Furthermore, the higher salinity induced by brine discharge can also impact the nutrient levels, in the absence of well-mixed behaviour of the water column.

The circulation in the Gulf is dominated by a basin scale, elongated cyclonic eddy during March-July (Thoppil and Hogan, 2010). In the context of currents prevailing in these eddy regimes, the variation of surface layer $\mathrm{Chl}-\mathrm{a}$ is analysed for both summer and winter periods for Stn. 5 (Figure 7). It is evident that relatively stronger southeasterly currents during September bring-in nutrient rich waters of the upwelling eddies present in the central Gulf, and leads to the enhancement of $\mathrm{Chl}-\mathrm{a}$. However, during winter these eddies collapse and the nutrient supply through cyclonic eddies are reduced to the minimum.

Summary

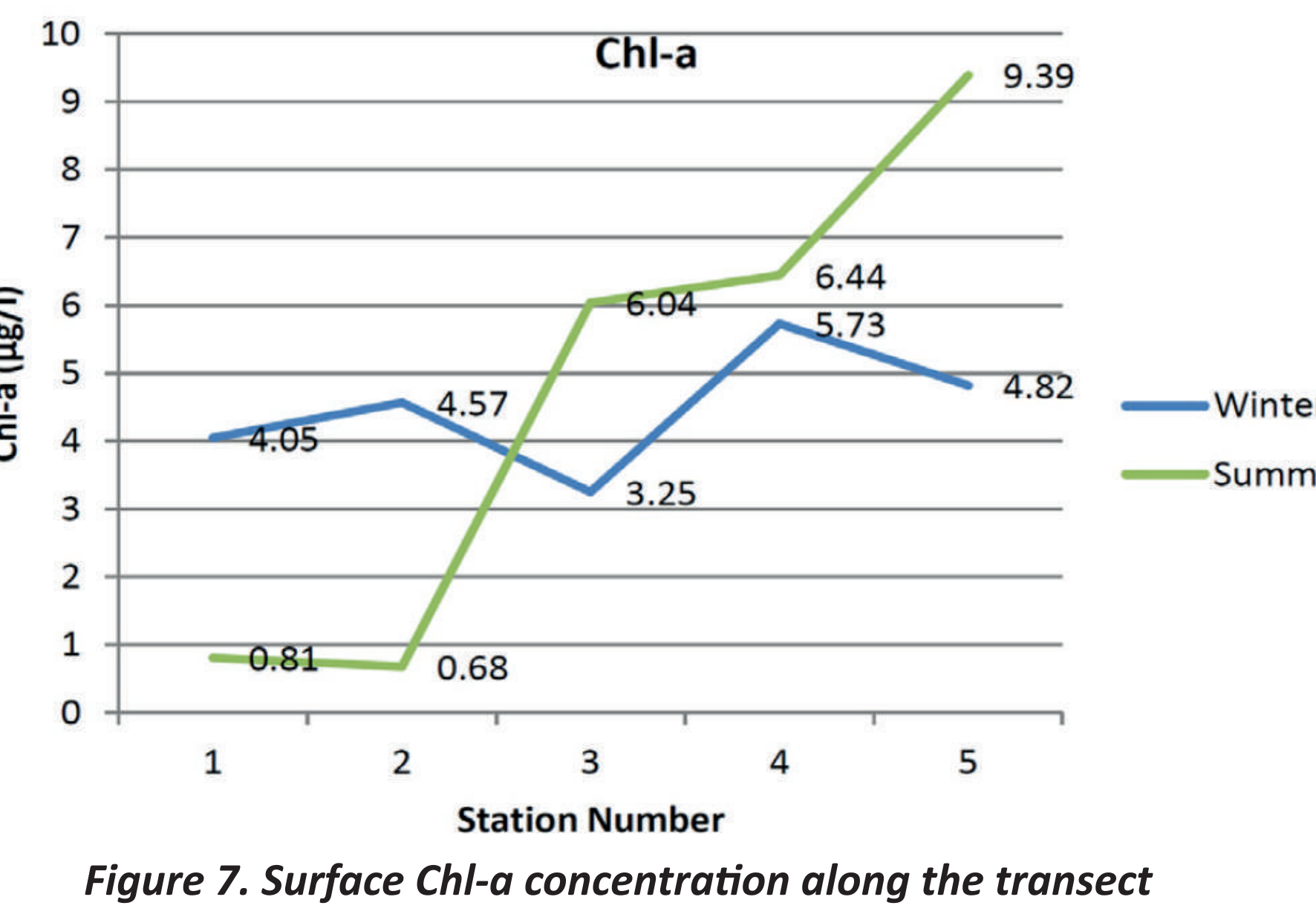

The temperature distribution along the transect shows well defined variations between late summer and winter, which is a characteristic feature of the Arabian Gulf waters. In winter, the upper layers are more homogenous than the late summer, with less vertical salinity variations. The salinity differences are not significantly different between the two seasons, but the temperature presents distinct variations. The well-mixed, cold waters during January allows the DO to be uniformly distributed with depth, while the stratified waters during September reduce the DO towards the deeper layers in the water column, leading to hypoxic conditions below $47 \mathrm{~m}$ depth. Furthermore, interesting variation is observed in Chl-a concentration between late summer and winter, and the fluctuation is quite high with depth during late summer, and homogenous during winter. The findings conclude that the productivity of the EEZ waters of Qatar is directly linked to eddy circulation in the central Gulf, winter cooling, wind mixing and disintegration of the cyclonic eddies. Hence, in order to make any assessment of the productivity of Qatari EEZ, the general circulation in the centra Gulf has to be investigated in detail.

\section{References}

\section{Aboobacker, $V . M$., Shanas, P.R, Veeras
potentials of Qatar, Energies, 14:1178}

Al-Ansari, I, 2, 2006. A Hydrographic
Newcastle, United Kingdom, 226 p

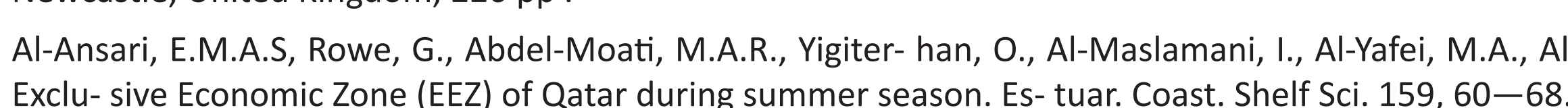

